\title{
Melatonin enhances porcine embryo development via the Nrf2/ARE signaling pathway
}

\author{
Eui Hyun Kim¹, Geon A Kim¹, Anukul Taweechaipaisankul1, Seok Hee Lee1, Muhammad Qasim¹, Curie Ahn² and \\ Byeong Chun Lee ${ }^{1}$
}

'Department of Theriogenology and Biotechnology, Research Institute for Veterinary Science, College of Veterinary Medicine, Seoul National University, Seoul, Republic of Korea

2Division of Nephrology, College of Medicine, Seoul National University, Seoul, Republic of Korea

Correspondence should be addressed to B C Lee: bclee@snu.ac.kr

\begin{abstract}
Oxidative stress (OS) is a major problem during in vitro culture of embryos. Numerous studies have shown that melatonin, which is known to have antioxidant properties, prevents the occurrence of OS in embryos. However, the molecular mechanisms by which melatonin prevents OS in embryos are still unclear. The present study suggests a possible involvement of the nuclear factor erythroid 2-related factor 2/antioxidantresponsive element ( $\mathrm{Nrf2/ARE)} \mathrm{signaling} \mathrm{pathway,} \mathrm{which} \mathrm{is} \mathrm{one} \mathrm{of} \mathrm{the} \mathrm{prominent} \mathrm{signals}$ for OS prevention through Nrf2 activation, connecting melatonin, OS prevention and porcine embryonic development. The aim of this study was to investigate the effects of melatonin (10-7 M) on porcine embryonic development via the Nrf2/ARE signaling pathway; brusatol (50 nM; Nrf2 specific inhibitor) was used to validate the mechanism. Treatment of porcine embryo with melatonin significantly increased formation rates of blastocysts and their total cell numbers and also upregulated the expression of Nrf2/ARE signaling and apoptosis-related genes (MT2, NRF2, UCHL, HO-1, SOD1 and BCL-2). Furthermore, the expression of proteins (NRF2 and MT2) was also upregulated in the melatonin-treated group. Concomitantly, brusatol significantly inhibited these effects, upregulating the expression of KEAP1 and BAX, including the expression level of KEAP1 protein. These results provide evidences that melatonin prevents OS through Nrf2/ARE signaling pathway in porcine in vitro fertilization -derived embryos.
\end{abstract}

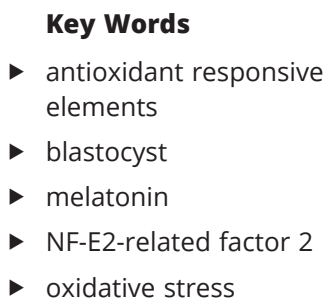

Journal of Molecular Endocrinology (2019) 63, 175-185

\section{Introduction}

Melatonin (N-acetyl-5-methoxytryptamine), a natural hormone, is synthesized by the mammalian pineal gland and peripheral reproductive organs, as well as being a byproduct from plants (Stehle et al. 2011). As is widely known, the functions of melatonin include regulating the circadian rhythm (Stehle et al. 2011), steroidogenesis (Macphee et al. 1975) and mammalian reproduction (Tamarkin et al. 1985). In addition, Reiter et al. postulated that, because melatonin was found to be a direct free radical scavenger, it stimulates antioxidative enzymes, thereby quenching free radicals (Reiter et al. 2016). Moreover, melatonin acts as an antioxidant via antioxidant-responsive element activities (Nguyen et al. 2009). Numerous studies have already demonstrated that 
treatment with an optimal concentration of melatonin during in vitro production (IVP) of embryos critically improves the quality of oocytes and determines subsequent embryonic development in various mammalian species, including mice (Tamura et al. 2008), cattle (Wang et al. 2014) and pigs (Rodriguez-Osorio et al. 2007, Jin et al. 2017, Lee et al. 2018). Although some studies identified intracellular mechanisms of melatonin action by evaluating oocyte maturation and embryo development, thereby improving IVP outcomes (Amin et al. 2014, Lee et al. 2017), it is still uncertain how this hormone works. Furthermore, no study has studied the enhancement of porcine embryonic development by melatonin via the nuclear factor erythroid 2-related factor 2/antioxidantresponsive element (Nrf2/ARE) signaling pathway.

Nuclear factor erythroid 2-related factor 2, also known as NFE2L2 or Nrf2, is a potential transcription factor that has antioxidative functions in cellular defense mechanisms (Lee \& Johnson 2004, Wells 2015). Moreover, there are numerous studies on Nrf2 signaling pathwayrelated antioxidation mechanisms in oocytes and embryos (Amin et al. 2014, Hahn et al. 2015, Akino et al. 2018, Lin et al. 2018). From these studies, it is generally accepted that Nrf2 translocates from the cytoplasm to the nucleus, binds to ARE sites, and then upregulates various enzymes responsible for producing cytoprotective compounds and proteins such as superoxide dismutase-1 (SOD1) and heme oxygenase-1 (HO-1) (Magesh et al. 2012). Such compounds that are activated by Nrf2 are also responsible for antioxidative functions related to cellular defense mechanisms (Lee \& Johnson 2004, Magesh et al. 2012, Wells 2015). Some factors that are related to the Nrf2/ARE signaling pathway regulate Nrf2 under numerous stimuli. Among these, Kelch-like ECH-associated protein 1 (KEAP1) is one of the fundamental factors. As a natural inhibitor of Nrf2, Keap1 in part mediates Nrf2 activity by repressing it, through ubiquitination that leads to proteasomal degradation. However, under oxidative stress (OS) conditions, Keap1 releases Nrf2 by altering its conformation, thereby activating it and initiating transcription (Nguyen et al. 2009, Kansanen et al. 2013, Ma 2013). However, this mechanism can be ceased by brusatol, a specific inhibitor of NRF2. It is a quassinoid isolated from the fruit of Brucea javanica and found to reduce burdens of tumor, mitigate chemoresistance in in vitro and in vivo cancer models (Ren et al. 2011, Tao et al. 2014, Wu et al. 2015), and most importantly, specifically inhibit Nrf2 via keap1-dependent ubiquitination and proteasomal degradation, thereby promotes a rapid depletion of Nrf2 (Olayanju et al. 2015).
Several studies have demonstrated that melatonin plays a critical role in regulation of the Nrf2/ARE signaling pathway by modulating various mechanisms involved with OS via Nrf2 cascades (Tripathi \& Jena 2010, Negi et al. 2011, Chen et al. 2017). Although some studies have associated the Nrf2/ARE signaling pathway with embryonic developments (Amin et al. 2014, Ma et al. 2017, Lin et al. 2018), further studies of their relationship are still needed including porcine species. Therefore, the aim of this study was to investigate if there is a direct impact and activation of Nrf2 transcripts by melatonin via the Nrf2/ARE signaling pathway in in vitro fertilization (IVF)-derived porcine preimplantation embryos.

\section{Materials and methods}

\section{Animals and chemicals}

The pig ovaries used in this study were obtained from a slaughter facility. They were not required to be screened by the Institutional Animal Care and Use Committee (IACUC) as the use of these ovaries are not regarded as an animal experiment in our university. All reagents and chemicals used in this study were obtained from SigmaAldrich Chemical Company, unless otherwise indicated.

\section{Chemical preparations}

Melatonin (Cat No. M5250) and brusatol (Cat No. SML1886) were purchased from Sigma-Aldrich and shipped as a powder form. DMSO was used as a solvent for melatonin and brusatol. Melatonin was dissolved in dimethyl sulfoxide (DMSO) to make a stock solution at the concentration of $10^{-2} \mathrm{M}$, then diluted $10^{-3}, 10^{-5}, 10^{-7}$, and $10^{-9} \mathrm{M}$ and brusatol at the concentration of $800 \mathrm{nM}$, and then diluted 50,200 , and $400 \mathrm{nM}$. Each concentration was treated in porcine zygote medium-5 (PZM-5; Funakoshi Corporation, Tokyo, Japan) and for the exact comparison, the same amount of DMSO was treated in the control groups.

\section{Oocyte recovery and in vitro maturation (IVM)}

Porcine ovaries were obtained from prepubertal gilts at a local abattoir and sent to the laboratory. Cumulusoocyte complexes (COCs) were retrieved by aspiration of 3-8 mm sized follicles with an 18-gauge needle fitted on a disposable $10 \mathrm{~mL}$ syringe, then washed two times in washing medium comprising $9.5 \mathrm{~g} / \mathrm{L}$ of medium-199 (M-199; Gibco), $2 \mathrm{mM}$ sodium bicarbonate, $0.3 \%$ polyvinyl alcohol (PVA), $5 \mathrm{mM}$ sodium hydroxide, $10 \mathrm{mM}$ N-piperazine- $\mathrm{N}^{\prime}$-[2-ethanesufonic acid], and 
1\% penicillin-streptomycin (Invitrogen). COCs with homogenous cytoplasm and three or more layers of cumulus cells were carefully selected under a stereomicroscope. They were cultured in in vitro maturation (IVM) medium comprising medium (M-199; Invitrogen), $0.91 \mathrm{mM}$ sodium pyruvate, $10 \mu \mathrm{L} / \mathrm{mL}$ insulin-transferrin-selenium solution 100× (Invitrogen), $10 \mathrm{ng} / \mathrm{mL}$ epidermal growth factor, $0.57 \mathrm{mM}$ cysteine, $10 \mathrm{IU} / \mathrm{mL}$ human chorionic gonadotropin, $10 \mathrm{IU} / \mathrm{mL}$ equine chorionic gonadotropin, and $10 \%$ porcine follicular fluid (vol/vol). The COCs were incubated at $39^{\circ} \mathrm{C}$ under $5 \% \mathrm{CO}_{2}$ in $95 \%$ humidified air. After $20-22 \mathrm{~h}$ of maturation culture with hormones, the COCs were washed in hormone-free IVM medium, and then cultured again in IVM medium without hormones for additional 20-22 h.

\section{In vitro fertilization (IVF)}

After $44 \mathrm{~h}$ of IVM, matured oocytes were denuded with $0.1 \%$ hyaluronidase by gently pipetting and washed in Tyrode's albumin lactate pyruvate (TALP) medium. Then, oocytes that had homogeneous cytoplasm and clear membranes with polar bodies were selected and moved to $40 \mu \mathrm{L}$ of pre-incubated modified Tris-buffered medium (mTBM) drops, consisting of $113.10 \mathrm{mM} \mathrm{NaCl}, 3 \mathrm{mM} \mathrm{KCl}, 7.50 \mathrm{mM}$ $\mathrm{CaCl}_{2}, 11 \mathrm{mM}$ glucose, $1 \mathrm{mM}$ caffeine, $0.57 \mathrm{mM}$ L-cysteine, $20 \mathrm{mM}$ Tris, and $8 \%$ bovine serum albumin (BSA) (w/v) in a $60 \times 10$ mm Petri dish (Falcon; Becton Dickinson Labware). Ejaculated spermatozoa were obtained from DARBY Pig Breeding Co. (Anseong, Korea). The semen was centrifuged at $1000 \mathrm{~g}$ for $2 \mathrm{~min}$, and the sperm pellet was resuspended with prewarmed porcine semen extender (Navibiotech, Cheonan, Korea). Then, the spermatozoa were centrifuged again at $1000 \mathrm{~g}$ for $2 \mathrm{~min}$. Immediately before the next process, sperm motility was evaluated and $>90 \%$ motile spermatozoa were used in each replication. Swim-up procedures were performed at $39^{\circ} \mathrm{C}$ in Sperm- Tyrode's Albumin Lactate Pyruvate (Sp-TALP) medium, and then spermatozoa were injected into mTBM droplets at a final concentration of $5 \times 10^{5}$ cells $/ \mathrm{mL}$. After a 6 -h coincubation of oocytes and spermatozoa, zygotes with second polar bodies were washed in mTBM droplets by gently pipetting, then transferred to $40 \mu \mathrm{L}$ droplets of PZM-5, covered with prewarmed mineral oil, and cultured at $39^{\circ} \mathrm{C}$ in a humidified atmosphere of $5 \% \mathrm{O}_{2}, 5 \% \mathrm{CO}_{2}$, and $90 \% \mathrm{~N}_{2}$ for 7 days.

\section{Embryo evaluation and total cell count after IVF}

The day of IVF, when presumptive zygotes were transferred to in vitro culture (IVC) medium, PZM-5, was considered
Day 0. Evenly cleaved embryos were monitored under a stereomicroscope on Day 2 (48h). Blastocyst formation was evaluated on Day 7 (168h) after IVF and total cell numbers were counted. Zona pellucida (ZP) digestion was performed with $0.5 \%$ pronase to remove remaining attached spermatozoa. After washing in TALP medium, zona-free blastocysts were stained with $5 \mu \mathrm{g} / \mathrm{mL}$ of Hoechst 33342 for $8 \mathrm{~min}$. After a final wash in TALP medium, stained blastocysts were mounted on glass slides in $100 \%$ glycerol drops, compressed with a cover slip, and observed under a fluorescence microscope (Nikon Corp.) at $400 \times$ magnification.

\section{Immunofluorescence staining}

Indirect immunofluorescence staining was performed in order to evaluate and compare the expression levels of NRF2, KEAP1, and MT2 among treatment groups after IVF. IVF porcine blastocysts were selected and ZP was removed with $0.5 \%$ pronase in order to remove remaining attached spermatozoa. Then, washed in PBS containing 1\% PVA, then, fixed with $4 \%$ paraformaldehyde $(\mathrm{w} / \mathrm{v})$ in phosphate buffered saline (PBS) for at least $2 \mathrm{~h}$, permeabilized with $1 \%$ Triton X-100 (v/v) in distilled water (DW) for $1 \mathrm{~h}$ at $39^{\circ} \mathrm{C}$, washed four times in 1\% PVA in DW, and incubated in DW containing 2\% BSA for $2 \mathrm{~h}$ in order to block nonspecific sites. Then, blastocysts were directly transferred into $2 \%$ BSA containing primary antibody for Nrf2 (1:200; 70R-50116; Fitzgerald Industries International, Acton, MA, USA), Keap1 ( $4 \mu \mathrm{L} / \mathrm{mL}$; ab218815; Abcam), and MT2 (1:200; ARP64072_P050; Aviva Systems Biology, San Diego, CA, USA) and incubated at $4^{\circ} \mathrm{C}$, overnight. Subsequently, they were washed three times in PBS with 1\% PVA and incubated with a secondary fluorescein isothiocyanate-conjugated anti-rabbit polyclonal antibody (1:200, ab6717, Abcam) at $37^{\circ} \mathrm{C}$ for $1.5 \mathrm{~h}$ in darkness. The blastocysts were washed three times in PBS with 1\% PVA, and then counterstained with $5 \mu \mathrm{g} / \mathrm{mL}$ Hoechst-33342 for $8 \mathrm{~min}$. They were mounted on glass slides and observed under a fluorescence microscope. The fluorescence measurements were performed using ImageJ software (version 1.46r; National Institute of Health, USA) and at least ten blastocysts from each group were used for the staining.

\section{Analysis of gene expression by quantitative real-time PCR}

IVF-derived blastocysts of each groups on Day 7 were stored at $-80^{\circ} \mathrm{C}$ until RNA was extracted. A total of 30 
blastocysts from each group were used for RNA extraction by the RNAqueous ${ }^{\mathrm{TM}}$ Micro Kit (Invitrogen). The total RNA was quantified on a NanoDrop 2000 Spectrophotometer (Thermo Fisher Scientific), and then immediately used for synthesizing cDNA using amfiRivert cDNA synthesis Platinum Master Mix 0 (genDEPOT, Houston, TX, USA) according to the manufacturer's protocol. For quantitative real-time PCR, each reaction mixture contained $1 \mu \mathrm{LcDNA}$, $0.4 \mu \mathrm{L}(10 \mathrm{pmol} / \mu \mathrm{L})$ forward primer, $0.4 \mu \mathrm{L}(10 \mathrm{pmol} / \mathrm{mL})$ reverse primer, $10 \mu \mathrm{L}$ SYBR Premix Ex Taq (Takara), and $8.2 \mu \mathrm{L}$ of nuclease-free water in a PCR plate (Micro-Amp Optical 96-Well Reaction Plate, Applied Biosystems). The mixture was amplified using the Applied Biosystems StepOneTM Real-Time PCR Systems (Applied Biosystems). For each sample, at least three replications were done in a plate. Forty cycles of reactions were performed with the following parameters: denaturation for $15 \mathrm{~s}$ at $95^{\circ} \mathrm{C}$, annealing for $1 \mathrm{~min}$ at $60^{\circ} \mathrm{C}$ and extension for $1 \mathrm{~min}$ at $72^{\circ} \mathrm{C}$. The sequences of primers used in this study are listed in Table 1. The expression of each target gene was quantified relative to that of the endogenous control gene $(G A P D H)$ (Lee et al. 2017). Genes of interest were verified and considered as available data with three categories: (1) Efficiency $(\%)=\left(10^{-1 / \text { slope }}-1\right) \times 100$, (2) $\mathrm{C}_{\mathrm{T}}$ values ranged from $>8$ to $<35$, (3) $R^{2}$ value $>0.98$. The relative expression of each target gene was calculated using the following equation (Jin et al. 2017):

$$
R=2^{-[\Delta C t \text { sample }-\Delta C t \text { control }]}
$$

\section{Statistical analysis}

Each experiment was performed at least in triplicates. Statistical analysis was performed using GraphPad Prism 5.01 (PRISM 5, GraphPad Software, Inc.). To determine the significant differences among experimental groups, data were expressed as the mean \pm S.E.M. and analyzed using univariate analysis variance with Tukey's multiple comparison test. $P$ values $<0.05$ were considered to be significantly different among the treatments.

\section{Results}

\section{Effect of melatonin treatment during IVC}

In the first experiment, several concentrations $\left(0,10^{-3}\right.$, $10^{-5}, 10^{-7}$ and $10^{-9} \mathrm{M}$ ) of melatonin were included during IVC to determine the optimal concentration. Melatonin treatment showed no significant differences on cleavage rate among the groups. However, there were significant differences in blastocyst formation rate and total cell numbers. Treatment with $10^{-7} \mathrm{M}$ melatonin significantly increased the porcine blastocyst formation rate compared to the control, $10^{-3}, 10^{-5}$ and $10^{-9} \mathrm{M}$ melatonin concentrations $(29.5$ vs $15.7 \%$, $11.0,18.3$, and $16.9 \%$, respectively, $P<0.05$, Table 2 ). Total cell numbers of blastocysts were also significantly increased when embryos were treated with $10^{-5}, 10^{-7}$ and $10^{-9} \mathrm{M}$ melatonin compared to control and the $10^{-3} \mathrm{M}$ melatonin $(84.3,83.3,87.0$ vs 65.0 and $44.0, P<0.05$, Table 2). However, $10^{-3} \mathrm{M}$ melatonin group showed the lowest number of cells in blastocysts among all groups $(P<0.05)$. Consequently, $10^{-7} \mathrm{M}$ melatonin was chosen as the optimal concentration for subsequent experiments because it showed the highest blastocyst formation rate among the groups (Table 2).

\section{The inhibitory effect of brusatol treatment during IVC}

In the second experiment, the concentrations of brusatol used were $0,50,200$ and $400 \mathrm{nM}$ according to a previous study on brusatol treatment of mouse embryos (Lin et al. 2018). Treatment with brusatol significantly decreased every steps of the porcine embryo development - cleavage rate, blastocyst formation rate, and total cell number of

Table 1 Information on primer sequences for real-time PCR.

\begin{tabular}{|c|c|c|c|c|}
\hline \multirow[b]{2}{*}{ Genes } & \multicolumn{2}{|c|}{ Primer sequences $\left(5^{\prime}-3^{\prime}\right)$} & \multirow[b]{2}{*}{ Product size $(b p)$} & \multirow[b]{2}{*}{ Accession No. } \\
\hline & Forward & Reverse & & \\
\hline GAPDH & GTCGGTTGTGGATCTGACCT & TTGACGAAGTGGTCGTTGAG & 207 & NM_001206359 \\
\hline MT2 & AGCTGCCTTAACGCCATCAT & ATTGTCGCCCAGTCAGTGAG & 219 & XM 021063941.1 \\
\hline Nrf2 & GCCCAGTCTTCATTGCTCCT & AGCTCСTCCCAAACTTGСTC & 115 & XM_013984303 \\
\hline Keap1 & ACCCAATTTCTGCCССТGAG & ACTTGACCTGCAGCGTAACA & 214 & NM_001114671 \\
\hline UCHL 1 & CCCTTCGCTTTATCCCCGTT & CGCTTATCTGCAGACCCCAA & 117 & NM_213763 \\
\hline SOD1 & TGACTGCTGGCAAAGATGGT & TTTCCACСТCTGCCCAAGTC & 133 & NM_001190422 \\
\hline $\mathrm{HO}-1$ & ACCCAGGACACTAAGGACCA & CGGTTGCATTCACAGGGTTG & 227 & NM_001004027 \\
\hline$B a x$ & CATGAAGACAGGGGCCCTTT & САTССТСTGCAGСTCCATGT & 181 & XM_003127290 \\
\hline$B C l-2$ & AGGGCATTCAGTGACCTGAC & CGATCCGACTCACCAATACC & 193 & NM_214285 \\
\hline
\end{tabular}


Table 2 Effect of melatonin during IVC on embryonic development after IVF.

\begin{tabular}{|c|c|}
\hline Chemicals (M) & $\begin{array}{c}\text { No. of embryos } \\
\text { cultured }\end{array}$ \\
\hline Control (0) & 185 \\
\hline $10^{-9}$ & 190 \\
\hline $10^{-7}$ & 188 \\
\hline $10^{-5}$ & 184 \\
\hline $10^{-3}$ & 185 \\
\hline
\end{tabular}

\begin{tabular}{ccc}
\hline No. of embryos developed to (mean \pm S.E.M. $\left.{ }^{*}, \%\right)$ \\
\hline$\geq 2$ cells & & Blastocyst \\
\hline $145(76.67 \pm 5.30)$ & & $22(15.73 \pm 1.39)^{a}$ \\
$158(83.07 \pm 5.28)$ & & $32(16.87 \pm 2.28)^{a}$ \\
$161(84.03 \pm 3.92)$ & & $56\left(29.48 \pm 1.66{ }^{b}\right.$ \\
$139(76.33 \pm 4.69)$ & & $31(18.25 \pm 3.72)^{a}$ \\
$139(74.40 \pm 3.21)$ & $20(11.00 \pm 0.80)^{a}$ \\
\hline
\end{tabular}

\begin{tabular}{c}
\hline $\begin{array}{c}\text { Total blastocyst cell number } \\
\left(\text { mean } \pm \text { S.E.M. }{ }^{*}\right)\end{array}$ \\
\hline $65.00 \pm 4.79 a$ \\
$87.00 \pm 3.08^{c}$ \\
$83.25 \pm 3.68 c$ \\
$84.25 \pm 2.93^{c}$ \\
$44.00 \pm 2.48^{b}$
\end{tabular}

*Six replicates were carried out. ANOVA was used as the statistical method. a,b,cValues with different superscripts in the same column are significantly different $(P<0.05)$.

blastocyst. The $400 \mathrm{nM}$ brusatol-treated group showed the lowest cleavage rate compared to control, 50 and $200 \mathrm{nM}$ (73.7 vs 93.4\%, 84.6, and $81.4 \%$, respectively, $P<0.05$, Table 3). Moreover, the effect of brusatol was evaluated on blastocyst formation rate, and all treatment groups (50, 200 and $400 \mathrm{nM}$ ) showed a significant decrease compared to control (5.6, 1.5 and 1.8 vs $14.8 \%$, respectively, $P<0.05)$. Lastly, total cell numbers of blastocysts were significantly decreased in all brusatol-treated groups (50, 200 and $400 \mathrm{nM})$ compared to control (38.3, 29.3 and 28.7 vs 56.5 , respectively, $P<0.05)$. Therefore, $50 \mathrm{nM}$ brusatol was considered as the optimal concentration of inhibiting Nrf2 transcription factor for the subsequent experiment.

\section{Inverse effects of melatonin and brusatol treatment during IVC}

To our knowledge, melatonin and brusatol have opposite functions when regulating NRF2, therefore, to investigate the inverse effects of melatonin and brusatol, they were co-treated during IVC on subsequent embryonic development after IVF. The melatonin-treated group showed a significant increase in blastocyst formation rate compared to the control and brusatol groups $(24.65$ vs $15.55 \%$ and $10.13 \%$, respectively, $P<0.05$, Table 4 ). Moreover, embryos treated with melatonin showed a significant difference in blastocyst total cell number compared to the control, brusatol and co-treated groups (78.80 vs 52.60, 48.00 and 57.40, respectively, $P<0.05$ ). However, there were no differences in cleavage rate. This result demonstrates the inverse effects of melatonin and brusatol on blastocyst formation rate and a possible effect of restoration in the co-treated group (Table 4).

\section{Effect of melatonin and brusatol treatment during IVC on gene expression in IVF-derived porcine blastocysts}

The expression of genes shown in Table 1 was investigated in IVF-derived porcine blastocysts. Figure 1A shows gene expression levels related to the melatonin receptor and the Nrf2/ARE signaling pathway and melatonin significantly increased mRNA transcript levels of MT2, Nrf2 and UCHL1 with no expression difference of Keap1 in porcine blastocysts compared to control $(P<0.05)$. Unlike in other groups, the co-treatment group showed the same increase of UCHL1 as the melatonin-treated group and the highest increase in MT2 transcript level. In the brusatoltreated group, expression of Nrf2 gene was significantly downregulated and expression of Keap1 upregulated compared to control. Additionally, mRNA transcript levels related to ARE were examined (Fig. 1A). The expression levels of HO-1 and SOD1 were significantly increased in the melatonin-treated group, and SOD1 was decreased in the brusatol-treated group compared to control; however, no difference was observed in $\mathrm{HO}-1$ expression. Lastly, as shown in Fig. 1, the expression levels of Bax and $\mathrm{BCl}-2$, the apoptosis-related gene, were evaluated in porcine blastocysts. The mRNA transcript level of Bax was significantly increased in the brusatol-treated and

Table 3 Effect of brusatol during IVC on embryonic development after IVF.

\begin{tabular}{lcc}
\hline Concentrations $(\mathrm{nM})$ & & $\begin{array}{c}\text { No. of embryos } \\
\text { cultured }\end{array}$ \\
\hline Control & 177 \\
50 & 180 \\
200 & 181 \\
400 & 185 \\
\hline
\end{tabular}

\begin{tabular}{|c|c|}
\hline \multicolumn{2}{|c|}{ No. of embryos developed to (mean \pm S.E.M. $\left.{ }^{*}, \%\right)$} \\
\hline$\geq 2$ cells & Blastocyst \\
\hline $165(93.40 \pm 1.29)^{a}$ & $24(14.86 \pm 1.59)^{a}$ \\
\hline $155(84.58 \pm 3.39)^{a}$ & $10(5.56 \pm 1.07)^{b}$ \\
\hline $149(81.42 \pm 3.72)^{a}$ & $3(1.48 \pm 0.92)^{b}$ \\
\hline $138(73.70 \pm 5.92)^{a}$ & $3(1.80 \pm 1.30)^{b}$ \\
\hline
\end{tabular}

\begin{tabular}{c}
$\begin{array}{c}\text { Total blastocyst cell number } \\
(\text { mean } \pm \text { S.E.M. *) }\end{array}$ \\
\hline $56.50 \pm 1.56^{\mathrm{a}}$ \\
$38.25 \pm 2.18^{\mathrm{b}}$ \\
$29.33 \pm 3.76^{\mathrm{b}}$ \\
$28.67 \pm 1.45^{\mathrm{b}}$
\end{tabular}

*Five replicates were carried out. ANOVA was used as the statistical method. a,bValues with different superscripts in the same column are significantly different $(P<0.05)$. 
Table 4 Co-treatment effects of melatonin and brusatol during IVC on embryonic development after IVF.

\begin{tabular}{|c|c|c|c|c|}
\hline \multirow[b]{2}{*}{ Chemicals } & \multirow{2}{*}{$\begin{array}{l}\text { No. of embryos } \\
\text { cultured }\end{array}$} & \multicolumn{2}{|c|}{ No. of embryos developed to (mean \pm S.E.M. $\left.{ }^{*}, \%\right)$} & \multirow{2}{*}{$\begin{array}{c}\text { Total blastocyst cell number } \\
(\text { (mean } \pm \text { S.E.M.) }\end{array}$} \\
\hline & & $\geq 2$ cells & Blastocyst & \\
\hline Control & 187 & $163(86.99 \pm 2.52)$ & $29(15.55 \pm 1.13)^{a}$ & $52.60 \pm 4.73^{a}$ \\
\hline Melatonin & 183 & $162(88.35 \pm 2.83)$ & $45(24.65 \pm 1.65)^{b}$ & $78.80 \pm 3.04^{b}$ \\
\hline Brusatol & 197 & $157(79.41 \pm 3.25)$ & $20(10.13 \pm 1.26)^{c}$ & $48.00 \pm 2.21^{a}$ \\
\hline Mtn + Bru & 193 & $167(86.42 \pm 1.22)$ & $29(14.98 \pm 1.09)^{a, c}$ & $57.40 \pm 1.57 a$ \\
\hline
\end{tabular}

*Five replicates were carried out. ANOVA was used as the statistical method. a,b,c Values with different superscripts in the same column are significantly different $(P<0.05)$. Mtn, 10-7 M melatonin; Bru, $50 \mathrm{nM}$ brusatol. aANOVA.

co-treated groups compared to control $(P<0.05)$, although the co-treated group was significantly lower than the brusatol-treated group. Lastly, the expression level of $\mathrm{Bcl}$ 2 was observed to be the highest in the melatonin and co-treated groups.

\section{Assessment of MT2, Nrf2, and Keap1 levels by immunofluorescence staining}

To elucidate the effects of these agents at the protein levels, we analyzed the presence of specific proteins related to the Nrf2/Keap1 signaling pathway in porcine blastocysts. In Fig. 2, MT2 was detected in all experimental groups and the highest intensity was observed in the melatonintreated group compared to the control, brusatol and co-treated groups $(P<0.05)$. As shown in Fig. 3, there was a significant increase of Nrf2 protein intensity in melatonintreated blastocysts compared to other groups $(P<0.05)$. Protein expression level of Keap1 was also examined by immunocytochemistry (Fig. 4A). The intensity of the brusatol-treated and co-treated groups were significantly increased compared to the other groups $(P<0.05$, Fig. 4B).

\section{Discussion}

For the first time, our study examined the role of the Nrf2/ARE signaling pathway in development of porcine preimplantation embryos by treating them with melatonin. Our results provide evidence that communications between melatonin and the Nrf2/ARE signaling pathway improved porcine embryo IVC, regulation of the Nrf2 cascade-related gene transcript levels, and subsequent protein expression in the blastocysts. Moreover, increased mRNA transcript levels were prevented by the Nrf2-specific inhibitor, brusatol. This implies that melatonin improves embryonic development and increases the expression of Nrf2/ARE signaling genes and protein expression levels in accordance with our hypothesis.
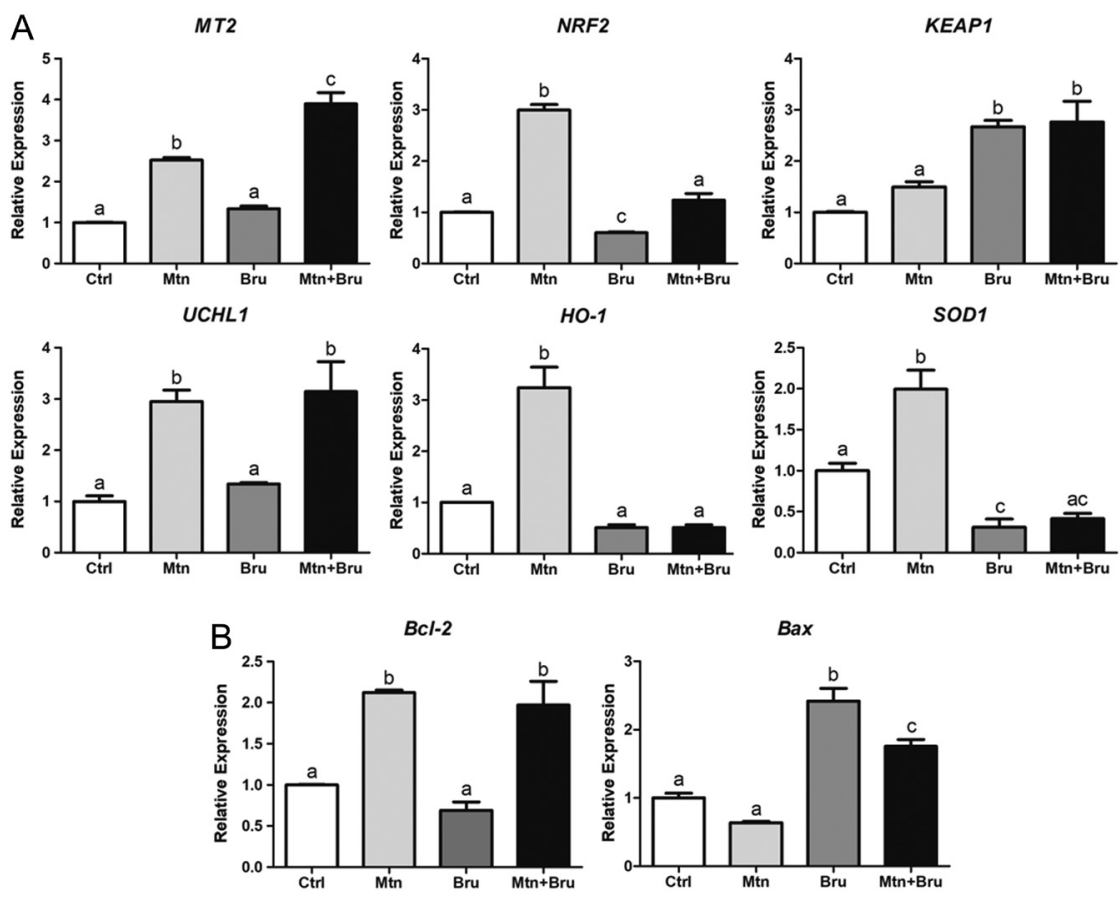

\section{Figure 1}

Effect of $10^{-7} \mathrm{M}$ melatonin on expression of $\mathrm{Nrf2/}$ ARE signaling pathway-related genes in IVFderived porcine blastocysts. (A) Nrf2/ARE signaling pathway-related genes (MT2, Nrf2, Keap1, UCHL1, SOD1, and HO-1). (B) Apoptosis-related genes (Bax and $\mathrm{BCl}-2)$. Within the same mRNA, bars with different alphabetical letters are significantly different among the groups $(P<0.05)$. The experiment was replicated at least three times. 


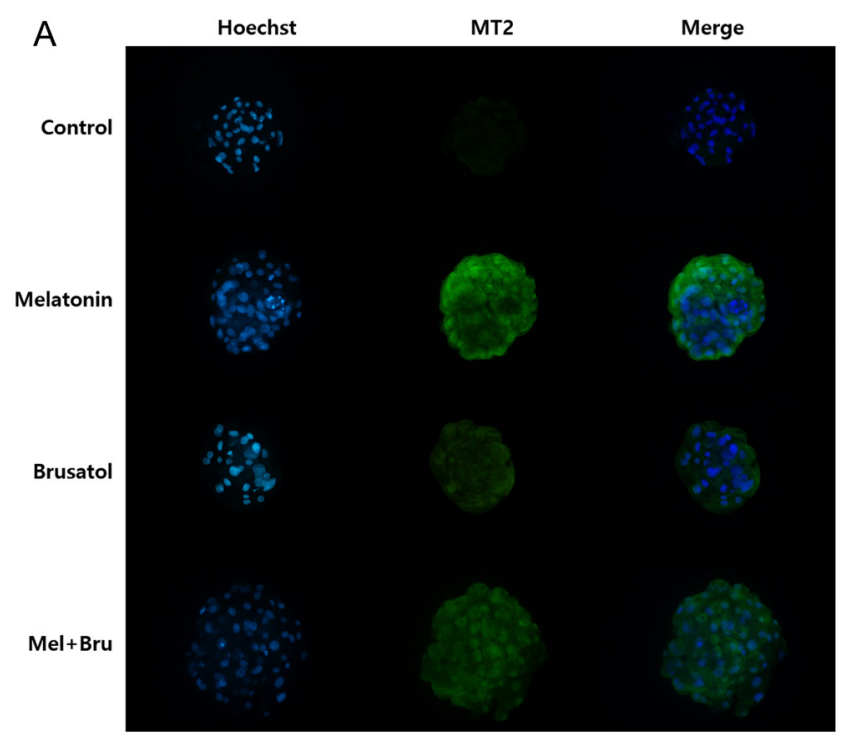

B

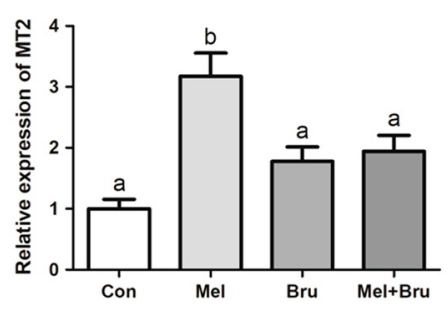

Figure 2

Immunocytochemical analysis of MT2 in porcine blastocysts. (A) Images of blastocysts were obtained by fluorescence microscopy. Representative in vitro-fertilized porcine blastocysts in each groups were stained with MT2 and counterstained with Hoechst 33342. (B) Statistical analysis of 10-7 M melatonin, $50 \mathrm{nM}$ brusatol, and co-treatment effects on MT2 protein expression in porcine blastocysts. Five replicates were carried out for this experiment. Data are shown as the means \pm s.E.M. Groups marked with different alphabetical letters are significantly different $(P<0.05)$. Mtn, $10^{-7} \mathrm{M}$ melatonin; Bru, $50 \mathrm{nM}$ brusatol. Original magnification 200x. A full colour version of this figure is available at https://doi.org/10.1530/JME-19-0093.

Previous studies suggesting that the role of melatonin during porcine embryo development is pivotal and optimized concentrations of melatonin were treated during IVC in order to prove its effects (Rodriguez-Osorio et al. 2007, Choi et al. 2008, Nakano et al. 2012, Do et al. 2015). Possible reasons for the inconsistencies might be different experimental methods, gas conditions during incubation or culture conditions such as media compounds and even differences within species (Rodriguez-Osorio et al. 2007, Nakano et al. 2012, Do et al. 2015). Therefore, we optimized the melatonin concentration to establish the appropriate concentration in our experimental environment. In our results, $10^{-7} \mathrm{M}$ melatonin was considered to be the optimal concentration for subsequent experiments. This is consistent with the fact that melatonin is effective at antioxidation during porcine IVC (Rodriguez-Osorio et al.
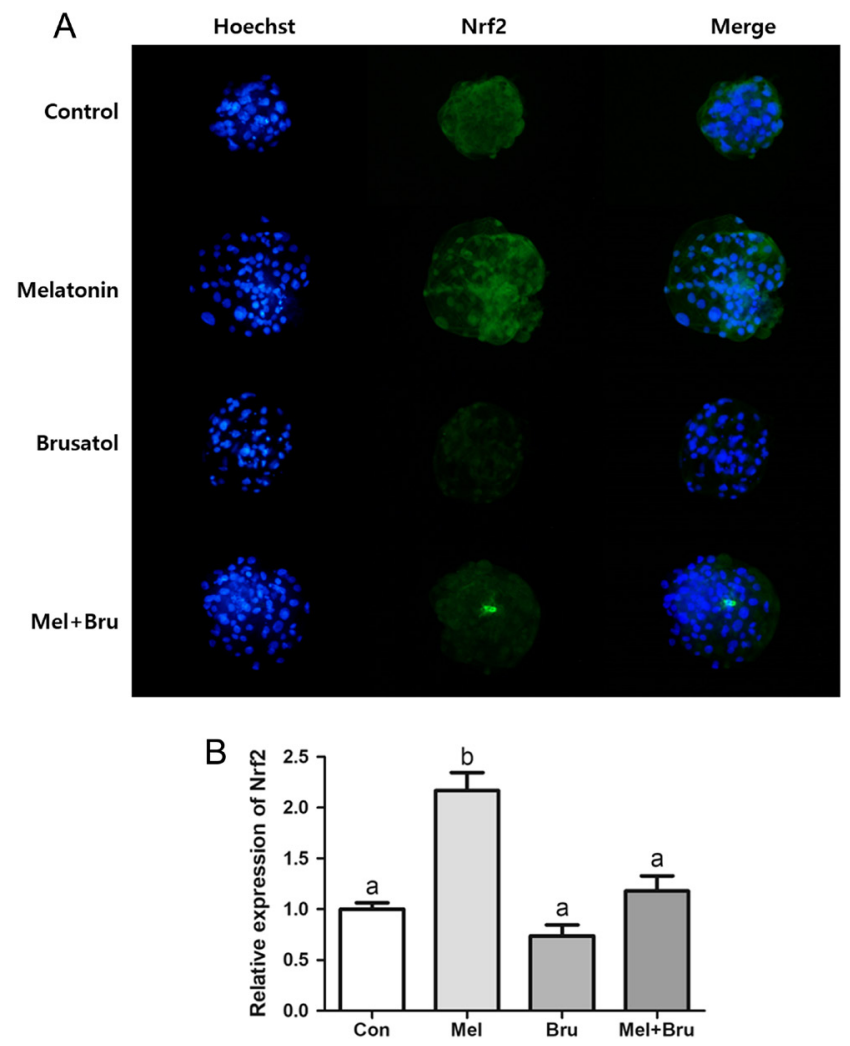

\section{Figure 3}

Immunocytochemical analysis of nuclear factor erythroid 2-related factor 2 in porcine blastocysts. (A) Representative in vitro-fertilized porcine blastocysts in each group were stained with nuclear factor erythroid 2-related factor 2 and counterstained with Hoechst 33342. (B) Statistical analysis of 10-7 M melatonin, $50 \mathrm{nM}$ brusatol, and co-treatment effects on nuclear factor erythroid 2-related factor 2 protein expression in porcine blastocysts. Six replicates were carried out for this experiment. Data are shown as the means \pm S.E.M. Groups marked with different alphabetical letters are significantly different $(P<0.05)$. Mtn, 10-7 M melatonin; Bru, $50 \mathrm{nM}$ brusatol. Original magnification $200 \times$. A full colour version of this figure is available at https://doi.org/10.1530/JME-19-0093.

2007, Choi et al. 2008, Nakano et al. 2012, Do et al. 2015). In contrast, $10^{-3} \mathrm{M}$ melatonin decreased the total cell number of blastocysts compared to control (Table 2) and this, being consistent with a previous study, supports the idea that $10^{-3} \mathrm{M}$ melatonin treatment during IVC of IVFderived porcine embryos may be detrimental for embryo development partially due to high concentration-induced toxicity (Rodriguez-Osorio et al. 2007).

Positive effects of melatonin treatment during IVM have also been reported: $10^{-9} \mathrm{M}$ melatonin was the most effective concentration for oocyte maturation, cumulus cell expansion, lipid content and even subsequent embryonic development via several signaling pathways such as sonic hedgehog signaling and the pentose phosphate pathway (Shi et al. 2009, Alvarez et al. 2013, Jin et al. 2017, Lee et al. 2017, 2018). On the other hand, 

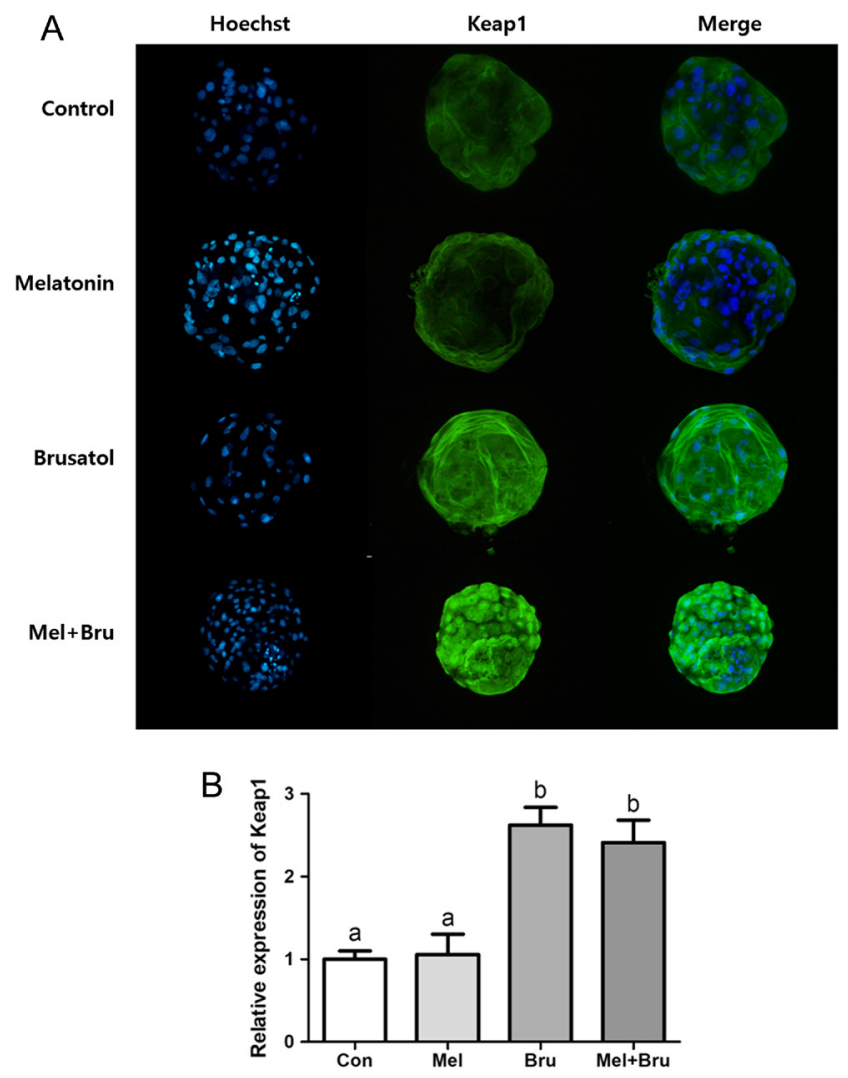

Figure 4

Immunocytochemical analysis of Kelch-like $\mathrm{ECH}$-associated protein 1 in porcine blastocysts. (A) Representative in vitro fertilized porcine blastocysts in each groups were stained with Kelch-like ECHassociated protein 1 and counterstained with Hoechst 33342. (B) Statistical analysis of $10^{-7} \mathrm{M}$ melatonin, $50 \mathrm{nM}$ brusatol, and co-treatment effects on Kelch-like ECH-associated protein expression in porcine blastocysts. Five replicates were carried out for this experiment. Data are shown as the means \pm s.E.M. Groups marked with different alphabetical letters are significantly different $(P<0.05)$. Mtn, 10-7 M melatonin; Bru, $50 \mathrm{nM}$ brusatol. Original magnification 200x. A full colour version of this figure is available at https://doi. org/10.1530/JME-19-0093.

investigations on modulation of specific pathways by melatonin during porcine IVC still need further details and clarification. Nrf2 is generally accepted as having crucial roles in upregulating the expressions of cytoprotective enzymes, cellular antioxidant defense system, and reproduction processes. (Leung et al. 2003, Lee \& Johnson 2004, Hu et al. 2006, Wells 2015, Akino et al. 2018). When activated, it in turn activates AREs to prevent OS (Nguyen et al. 2009, Wells 2015, Akino et al. 2018). In addition, blastocyst formation is a critical indicator for the efficiency of embryo development and culture conditions (Nomura et al. 2007) and the total cell number of blastocysts is a standard criterion for evaluating the quality of embryos (Knijn et al. 2003). Consequently, our results showed that melatonin was effective on increasing porcine embryonic development and regulated Nrf2 and its related genes (Keap1, UCHL1, SOD1, and HO-1) in porcine blastocysts in our experiment. Our results may support the fact that melatonin activates the Nrf2/ARE signaling pathway as demonstrated in previous studies (Tripathi \& Jena 2010, Negi et al. 2011, Chen et al. 2017, Guo et al. 2017).

Here, brusatol, the Nrf2-specific inhibitor, was applied to our study to specify whether melatonin truly functions as an antioxidant by regulating the Nrf2/ARE signaling pathway. Brusatol inhibits Nrf2 directly and specifically in many types of cells and oocytes by inducing a rapid depletion of Nrf2 (Olayanju et al. 2015, Ma et al. 2017). Moreover, it is proved that brusatol with micromolar concentrations inhibits protein synthesis of Nrf2, and also it inhibits Nrf2 transcription specifically with nanomolar concentrations (Ren et al. 2011). In Table 3, the negative effect is clearly shown and also the result is supported by the study of Lin et al. which showed that $50 \mathrm{nM}$ brusatol also had negative effects during IVC of mouse embryos (Lin et al. 2018). This supports our results shown in Fig. 1A and Table 3, and these results indicate that treatment with brusatol is detrimental for embryonic development in a dose-dependent manner. Therefore, our study demonstrated that brusatol inhibited the actions of Nrf2.

We hypothesized that melatonin would activate this pathway through melatonin receptor 2 (MT2), subsequently preventing OS during porcine IVP. At present, including MT2, other melatonin receptors are known such as MT1, in mammals, and MT3 in amphibians and birds (Reppert et al. 1996, Sugden et al. 2004). Moreover, they appear to be part of the superfamily of guanine nucleotide binding protein ( $G$ protein)-coupled receptors (GPCR) (Reppert 1997). It was suggested that the mechanism and abilities of melatonin to enhance the expansion of cumulus cells in COCs and oocytes independently and to enhance subsequent embryonic development is mediated by MT2 ( Lee et al. 2018) which implies that functions of MT2 is pivotal for melatonin mechanism during embryonic development. In Figs 1A and 2, MT2 was also expressed in the control and brusatol-treated groups. This can be explained by the study of Pala et al. that MT2 bindings can be achieved through non-specific hydrophobic interactions (Pala et al. 2013); moreover, brusatol is suitable for binding with MT2 because it is also known to have poor aqueous affinity (Zhou et al. 2017). To sum up, we presume that IVF-derived porcine blastocysts took up melatonin via MT2, and a result the blastocyst formation rate and total cell number of blastocysts were increased. 
In Fig. 3, our results may support the idea that melatonin is infused through MT2 into developing embryos, thereby activating AREs via the Nrf2/ARE signaling pathway. In particular, $H O-1$ and SOD1 are genes that are responsible for antioxidative mechanisms related to the Nrf2/ARE signaling pathway (Ma 2013, Akino et al. 2018, Lin et al. 2018). According to Fig. 1A, brusatol is closely related to SOD1 and downregulates its function. Although HO-1 has a close relationship with the Nrf2/ ARE signaling pathway, further studies of the possible cross-talk between brusatol and $\mathrm{HO}-1$ are needed because opposite effects on HO-1 by brusatol have been reported in some studies (Xu et al. 2015, Liu et al. 2019). Therefore, we speculate that brusatol has no effect on HO-1 at least in porcine preimplantation blastocysts, but affects Nrf2 and SOD1 regulation. Connections between melatonin and the Nrf2/ARE pathway may partially be explained by the expression of $\mathrm{Nrf2}$, because its expression level was inversely regulated in each treatments.

According to our results, because melatonin upregulated mRNA and protein expression level of NRF2, we next assumed that melatonin would also affect ubiquitination in Nrf2 and keap1 interaction. Therefore, along with the proteasomal degradation, UCHL1 can be a potential marker for deubiquitylation of enzymes from the proteasome system using ubiquitin because its decrease is related to decreased cell proliferation (Sanchez-Diaz et al. 2017). It is known that OS and apoptosis have mutual interactions (Kannan \& Jain 2000) and also the antioxidative mechanism of melatonin is closely involved in apoptosis of cells and embryos (Zhao et al. 2016, Lan et al. 2018). Therefore, Bcl-2 and $B a x$, apoptosis-related genes, were selected for analysis. Figure $1 \mathrm{~B}$ demonstrates that the apoptosis-related genes are regulated by both melatonin and brusatol.

Ren and colleagues have stated that cell lines had different statuses of Keap1, and in part, brusatol promoted Nrf2 degradation in a keap1-dependent manner depending on the types of cells (Ren et al. 2011). However, there are no studies on brusatol-Keap1 interaction in gametes or zygotes. Interestingly, as shown in Figs $1 \mathrm{~A}$ and 4 , the results may support the partial dependence of brusatol on Keap1. In brief, the actions of brusatol may depend directly on Keap1 at least in porcine blastocysts in accordance with our result. However, the mechanism by which brusatol depends on Keap1 warrants further investigation.

In this experiment, we hypothesized that through the uptake of melatonin by porcine embryos, melatonin directly activates and translocates Nrf2, and then AREs are produced. However, we applicated brusatol (the Nrf2 specific inhibitor) in order to verify that the activation of Nrf2 is truly affected by melatonin. We found that melatonin upregulated mRNA and protein expression level of MT2 in the porcine embryos (Figs 1A and 2) and also upregulated mRNA and protein expression level of Nrf2. Additionally, the inhibitory works of brusatol on Nrf2 was also observed in the porcine embryos after the uptake of melatonin. Altogether, we suggest a plausible interaction between a direct impact of melatonin through the Nrf2/ARE signaling pathway on porcine preimplantation embryos during IVC. The MT2 receptor, as one of the GPCRs, communicates with numerous pathways that activate antioxidative responses (Han et al. 2017, Lee et al. 2017) and among them, the Nrf2/ARE signaling pathway could be one of the potential pathways for embryo researches. As this is the first research into the mechanism of the Nrf2/ARE signaling pathway in porcine IVF-derived preimplantation embryos, further studies should be initiated in order to elucidate this mechanism.

\section{Declaration of interest}

The authors declare that there is no conflict of interest that could be perceived as prejudicing the impartiality of the research reported.

\section{Funding}

This work was supported by the National Research Foundation (\#2016M3A9B6903410; 2018R1D1A1B07048765).

\section{Author contribution statement}

Eui Hyun Kim conceived the study, carried out the experiments, then performed the statistical analysis and drafted the manuscript. Geon A Kim, Curie Ahn, and Byeong Chun Lee assisted with designing the experiment, statistical analysis of the data and manuscript drafting. Anukul Taweechaipaisankul, Seok Hee Lee, and Muhammad Qasim assisted with implementation of the experiments. All co-authors revised the manuscript. Byeong Chun Lee supervised the research and supplied the funding. All authors read, revised, and approved the final manuscript.

\section{Acknowledgements}

The authors would like to thank Bomi Woo and Do Yeon Kim (Staff at the Department of Theriogenology and Biotechnology, Seoul National University) for technical assistance and Sanghoon Lee for a critical revision of the manuscript. This study was supported by the Research Institute for Veterinary Science, Gyeonggi-do Livestock Promotion Center and the BK21 PLUS Program.

\section{References}

Akino N, Wada-Hiraike $\mathrm{O}$, Terao $\mathrm{H}$, Honjoh $\mathrm{H}$, Isono $\mathrm{W}, \mathrm{Fu} \mathrm{H}$, Hirano M, Miyamoto Y, Tanikawa M, Harada M, et al. 2018 Activation of Nrf2 might reduce oxidative stress in human granulosa cells. Molecular and Cellular Endocrinology 470 96-104. (https://doi. org/10.1016/j.mce.2017.10.002) 
Alvarez GM, Ferretti EL, Gutnisky C, Dalvit GC \& Cetica PD 2013 Modulation of glycolysis and the pentose phosphate pathway influences porcine oocyte in vitro maturation. Reproduction in Domestic Animals 48 545-553. (https://doi.org/10.1111/rda.12123)

Amin A, Gad A, Salilew-Wondim D, Prastowo S, Held E, Hoelker M, Rings F, Tholen E, Neuhoff C, Looft C, et al. 2014 Bovine embryo survival under oxidative-stress conditions is associated with activity of the NRF2-mediated oxidative-stress-response pathway. Molecular Reproduction and Development 81 497-513. (https://doi.org/10.1002/ mrd.22316)

Chen LY, Renn TY, Liao WC, Mai FD, Ho YJ, Hsiao G, Lee AW \& Chang HM 2017 Melatonin successfully rescues hippocampal bioenergetics and improves cognitive function following drug intoxication by promoting Nrf2-ARE signaling activity. Journal of Pineal Research 63. (https://doi.org/10.1111/jpi.12417)

Choi J, Park SM, Lee E, Kim JH, Jeong YI, Lee JY, Park SW, Kim HS, Hossein MS, Jeong YW, et al. 2008 Anti-apoptotic effect of melatonin on preimplantation development of porcine parthenogenetic embryos. Molecular Reproduction and Development 75 1127-1135. (https://doi.org/10.1002/mrd.20861)

Do LT, Shibata Y, Taniguchi M, Nii M, Nguyen TV, Tanihara F, Takagi M \& Otoi T 2015 Melatonin supplementation during in vitro maturation and development supports the development of porcine embryos. Reproduction in Domestic Animals 50 1054-1058. (https:// doi.org/10.1111/rda.12607)

Guo Y, Sun J, Li T, Zhang Q, Bu S, Wang Q \& Lai D 2017 Melatonin ameliorates restraint stress-induced oxidative stress and apoptosis in testicular cells via NF-kappaB/iNOS and Nrf2/ HO-1 signaling pathway. Scientific Reports 7 9599. (https://doi.org/10.1038/s41598017-09943-2)

Hahn ME, Timme-Laragy AR, Karchner SI \& Stegeman JJ 2015 Nrf2 and Nrf2-related proteins in development and developmental toxicity: insights from studies in zebrafish (Danio rerio). Free Radical Biology and Medicine 88 275-289. (https://doi.org/10.1016/j. freeradbiomed.2015.06.022)

Han L, Wang H, Li L, Li X, Ge J, Reiter RJ \& Wang Q 2017 Melatonin protects against maternal obesity-associated oxidative stress and meiotic defects in oocytes via the SIRT3-SOD2-dependent pathway. Journal of Pineal Research 63 e12431. (https://doi.org/10.1111/jpi.12431)

Hu X, Roberts JR, Apopa PL, Kan YW \& Ma Q 2006 Accelerated ovarian failure induced by 4-vinyl cyclohexene diepoxide in Nrf2 null mice. Molecular and Cellular Biology 26 940-954. (https://doi.org/10.1128/ MCB.26.3.940-954.2006)

Jin JX, Lee S, Taweechaipaisankul A, Kim GA \& Lee BC 2017 Melatonin regulates lipid metabolism in porcine oocytes. Journal of Pineal Research 62 e12388. (https://doi.org/10.1111/jpi.12388)

Kannan K \& Jain SK 2000 Oxidative stress and apoptosis. Pathophysiology 7 153-163. (https://doi.org/10.1016/S0928-4680(00)00053-5)

Kansanen E, Kuosmanen SM, Leinonen H \& Levonen AL 2013 The Keap1-Nrf2 pathway: mechanisms of activation and dysregulation in cancer. Redox Biology 1 45-49. (https://doi.org/10.1016/j. redox.2012.10.001)

Knijn HM, Gjorret JO, Vos PL, Hendriksen PJ, Van Der Weijden BC, Maddox-Hyttel P \& Dieleman SJ 2003 Consequences of in vivo development and subsequent culture on apoptosis, cell number, and blastocyst formation in bovine embryos. Biology of Reproduction 69 1371-1378. (https://doi.org/10.1095/biolreprod.103.017251)

Lan M, Han J, Pan MH, Wan X, Pan ZN \& Sun SC 2018 Melatonin protects against defects induced by deoxynivalenol during mouse oocyte maturation. Journal of Pineal Research 65 e12477. (https://doi. org/10.1111/jpi.12477)

Lee JM \& Johnson JA 2004 An important role of Nrf2-ARE pathway in the cellular defense mechanism. Journal of Biochemistry and Molecular Biology 37 139-143. (https://doi.org/10.5483/BMBRep.2004.37.2.139)

Lee S, Jin JX, Taweechaipaisankul A, Kim GA, Ahn C \& Lee BC 2017 Melatonin influences the sonic hedgehog signaling pathway in porcine cumulus oocyte complexes. Journal of Pineal Research $\mathbf{6 3}$ e12424. (https://doi.org/10.1111/jpi.12424)

Lee S, Jin JX, Taweechaipaisankul A, Kim GA \& Lee BC 2018 Stimulatory effects of melatonin on porcine in vitro maturation are mediated by MT2 receptor. International Journal of Molecular Sciences 191581. (https://doi.org/10.3390/ijms19061581)

Leung L, Kwong M, Hou S, Lee C \& Chan JY 2003 Deficiency of the Nrf1 and Nrf2 transcription factors results in early embryonic lethality and severe oxidative stress. Journal of Biological Chemistry 278 48021-48029. (https://doi.org/10.1074/jbc.M308439200)

Lin Y, Sui LC, Wu RH, Ma RJ, Fu HY, Xu JJ, Qiu XH \& Chen L 2018 Nrf2 inhibition affects cell cycle progression during early mouse embryo development. Journal of Reproduction and Development 64 49-55. (https://doi.org/10.1262/jrd.2017-042)

Liu X, Xu H, Zhang Y, Wang P \& Gao W 2019 Brusatol inhibits amyloid-beta-induced neurotoxicity in U-251 cells via regulating the Nrf2/HO-1 pathway. Journal of Cellular Biochemistry 120 1055610563. (https://doi.org/10.1002/jcb.28341)

Ma Q 2013 Role of nrf2 in oxidative stress and toxicity. Annual Review of Pharmacology and Toxicology 53 401-426. (https://doi.org/10.1146/ annurev-pharmtox-011112-140320)

Ma R, Li H, Zhang Y, Lin Y, Qiu X, Xie M \& Yao B 2017 The toxic effects and possible mechanisms of brusatol on mouse oocytes. PLOS ONE 12 e0177844. (https://doi.org/10.1371/journal.pone.0177844)

Macphee AA, Cole FE \& Rice BF 1975 The effect of melatonin on steroidogenesis by the human ovary in vitro. Journal of Clinical Endocrinology and Metabolism 40 688-696. (https://doi.org/10.1210/ jcem-40-4-688)

Magesh S, Chen Y \& Hu L 2012 Small molecule modulators of Keap1Nrf2-ARE pathway as potential preventive and therapeutic agents. Medicinal Research Reviews 32 687-726. (https://doi.org/10.1002/ med.21257)

Nakano M, Kato Y \& Tsunoda Y 2012 Effect of melatonin treatment on the developmental potential of parthenogenetic and somatic cell nuclear-transferred porcine oocytes in vitro. Zygote 20 199-207. (https://doi.org/10.1017/S0967199411000190)

Negi G, Kumar A \& Sharma SS 2011 Melatonin modulates neuroinflammation and oxidative stress in experimental diabetic neuropathy: effects on NF-kappaB and Nrf2 cascades. Journal of Pineal Research 50 124-131. (https://doi. org/10.1111/j.1600-079X.2010.00821.x)

Nguyen T, Nioi P \& Pickett CB 2009 The Nrf2-antioxidant response element signaling pathway and its activation by oxidative stress. Journal of Biological Chemistry 284 13291-13295. (https://doi. org/10.1074/jbc.R900010200)

Nomura M, Iwase A, Furui K, Kitagawa T, Matsui Y, Yoshikawa M \& Kikkawa F 2007 Preferable correlation to blastocyst development and pregnancy rates with a new embryo grading system specific for day 3 embryos. Journal of Assisted Reproduction and Genetics 24 23-28. (https://doi.org/10.1007/s10815-006-9086-5)

Olayanju A, Copple IM, Bryan HK, Edge GT, Sison RL, Wong MW, Lai ZQ, Lin ZX, Dunn K, Sanderson CM, et al. 2015 Brusatol provokes a rapid and transient inhibition of Nrf2 signaling and sensitizes mammalian cells to chemical toxicity-implications for therapeutic targeting of Nrf2. Free Radical Biology and Medicine $\mathbf{7 8}$ 202-212. (https://doi.org/10.1016/j.freeradbiomed.2014.11.003)

Pala D, Lodola A, Bedini A, Spadoni G \& Rivara S 2013 Homology models of melatonin receptors: challenges and recent advances. International Journal of Molecular Sciences 14 8093-8121. (https://doi. org/10.3390/ijms14048093)

Reiter RJ, Mayo JC, Tan DX, Sainz RM, Alatorre-Jimenez M \& Qin L 2016 Melatonin as an antioxidant: under promises but over delivers. Journal of Pineal Research 61 253-278. (https://doi.org/10.1111/ jpi.12360)

Ren D, Villeneuve NF, Jiang T, Wu T, Lau A, Toppin HA \& Zhang DD 2011 Brusatol enhances the efficacy of chemotherapy by inhibiting https://jme.bioscientifica.com

https://doi.org/10.1530/JME-19-0093
(C) 2019 Society for Endocrinology Published by Bioscientifica Ltd. Printed in Great Britain 
the Nrf2-mediated defense mechanism. PNAS 108 1433-1438. (https://doi.org/10.1073/pnas.1014275108)

Reppert SM 1997 Melatonin receptors: molecular biology of a new family of G protein-coupled receptors. Journal of Biological Rhythms 12 528-531. (https://doi.org/10.1177/074873049701200606)

Reppert SM, Weaver DR \& Godson C 1996 Melatonin receptors step into the light: cloning and classification of subtypes. Trends in Pharmacological Sciences 17 100-102. (https://doi.org/10.1016/0165-6147(96)10005-5)

Rodriguez-Osorio N, Kim IJ, Wang H, Kaya A \& Memili E 2007 Melatonin increases cleavage rate of porcine preimplantation embryos in vitro. Journal of Pineal Research 43 283-288. (https://doi. org/10.1111/j.1600-079X.2007.00475.x)

Sanchez-Diaz PC, Chang JC, Moses ES, Dao T, Chen Y \& Hung JY 2017 Ubiquitin carboxyl-terminal esterase L1 (UCHL1) is associated with stem-like cancer cell functions in pediatric high-grade glioma. PLoS ONE 12 e0176879. (https://doi.org/10.1371/journal.pone.0176879)

Shi JM, Tian XZ, Zhou GB, Wang L, Gao C, Zhu SE, Zeng SM, Tian JH \& Liu GS 2009 Melatonin exists in porcine follicular fluid and improves in vitro maturation and parthenogenetic development of porcine oocytes. Journal of Pineal Research 47 318-323. (https://doi. org/10.1111/j.1600-079X.2009.00717.x)

Stehle JH, Saade A, Rawashdeh O, Ackermann K, Jilg A, Sebesteny T \& Maronde E 2011 A survey of molecular details in the human pineal gland in the light of phylogeny, structure, function and chronobiological diseases. Journal of Pineal Research 51 17-43. (https://doi.org/10.1111/j.1600-079X.2011.00856.x)

Sugden D, Davidson K, Hough KA \& Teh MT 2004 Melatonin, melatonin receptors and melanophores: a moving story. Pigment Cell Research 17 454-460. (https://doi. org/10.1111/j.1600-0749.2004.00185.x)

Tamarkin L, Baird CJ \& Almeida OF 1985 Melatonin: a coordinating signal for mammalian reproduction? Science 227 714-720. (https:// doi.org/10.1126/science.3881822)

Tamura H, Takasaki A, Miwa I, Taniguchi K, Maekawa R, Asada H, Taketani T, Matsuoka A, Yamagata Y, Shimamura K, et al. 2008 Oxidative stress impairs oocyte quality and melatonin protects oocytes from free radical damage and improves fertilization rate. Journal of Pineal Research 44 280-287. (https://doi. org/10.1111/j.1600-079X.2007.00524.x)

Tao S, Wang S, Moghaddam SJ, Ooi A, Chapman E, Wong PK \& Zhang DD 2014 Oncogenic KRAS confers chemoresistance by upregulating NRF2. Cancer Research 74 7430-7441. (https://doi. org/10.1158/0008-5472.CAN-14-1439)

Tripathi DN \& Jena GB 2010 Effect of melatonin on the expression of Nrf2 and NF-kappaB during cyclophosphamide-induced urinary bladder injury in rat. Journal of Pineal Research $\mathbf{4 8} 324-331$. (https:// doi.org/10.1111/j.1600-079X.2010.00756.X)

Wang F, Tian X, Zhang L, Gao C, He C, Fu Y, Ji P, Li Y, Li N \& Liu G 2014 Beneficial effects of melatonin on in vitro bovine embryonic development are mediated by melatonin receptor 1. Journal of Pineal Research 56 333-342. (https://doi.org/10.1111/jpi.12126)

Wells G 2015 Peptide and small molecule inhibitors of the Keap1-Nrf2 protein-protein interaction. Biochemical Society Transactions 43674 679. (https://doi.org/10.1042/BST20150051)

Wu T, Harder BG, Wong PK, Lang JE \& Zhang DD 2015 Oxidative stress, mammospheres and Nrf2-new implication for breast cancer therapy? Molecular Carcinogenesis 54 1494-1502. (https://doi.org/10.1002/ mc.22202)

Xu X, Li H, Hou X, Li D, He S, Wan C, Yin P, Liu M, Liu F \& Xu J 2015 Punicalagin induces Nrf2/HO-1 expression via upregulation of PI3K/ AKT pathway and inhibits LPS-induced oxidative stress in RAW264.7 macrophages. Mediators of Inflammation 2015 380218. (https://doi. org/10.1155/2015/380218)

Zhao XM, Hao HS, Du WH, Zhao SJ, Wang HY, Wang N, Wang D, Liu Y, Qin T \& Zhu HB 2016 Melatonin inhibits apoptosis and improves the developmental potential of vitrified bovine oocytes. Journal of Pineal Research 60 132-141. (https://doi.org/10.1111/jpi.12290)

Zhou J, Tan L, Xie J, Lai Z, Huang Y, Qu C, Luo D, Lin Z, Huang P, Su Z, et al. 2017 Characterization of brusatol self-microemulsifying drug delivery system and its therapeutic effect against dextran sodium sulfate-induced ulcerative colitis in mice. Drug Delivery 24 16671679. (https://doi.org/10.1080/10717544.2017.1384521)

Received in final form 30 July 2019

Accepted 13 August 2019

Accepted Preprint published online 13 August 2019
(C) 2019 Society for Endocrinology Published by Bioscientifica Ltd. Printed in Great Britain 